\title{
El Clauer en Ibiza a partir de la documentación del s. XVII. (Aspectos formales, sociales y simbólicos)
}

\section{INTRODUCCIÓN}

El objeto de este estudio lo constituye el conjunto de cadena y manojo de llaves que, tradicionalmente, las mujeres ibicencas llevaban pendiendo desde la cintura por un lado del faldar.

Dada la conveniencia metodológica de tomar como punto de partida el momento más inmediato, para ir retrocediendo paulatinamente hasta llegar a lo más lejano, hemos juzgado oportuno el iniciar este trabajo de la misma forma que comenzamos a elaborarlo. Esto es, sirviéndonos de los últimos testimonios del clauer, entre los que destaca una vieja postal (Fig. 1), que nos demuestra además la relación de este conjunto de joyas con la indumentaria de carácter popular.

Dicha indumentaria aparece a su vez captada en alguna fotografía (Fig. 2) y en varias de las acuarelas (Fig. 3) realizadas en 1933 por los miem-

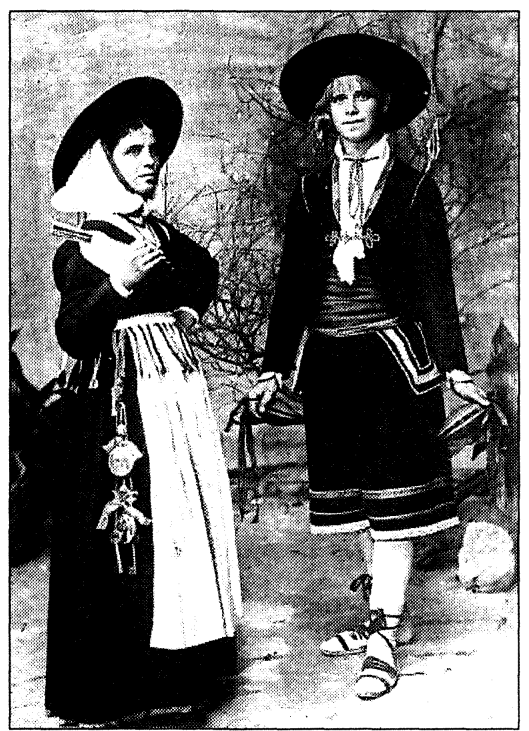

FIG. 1.-Pareja ibicenca (Foto Puget).

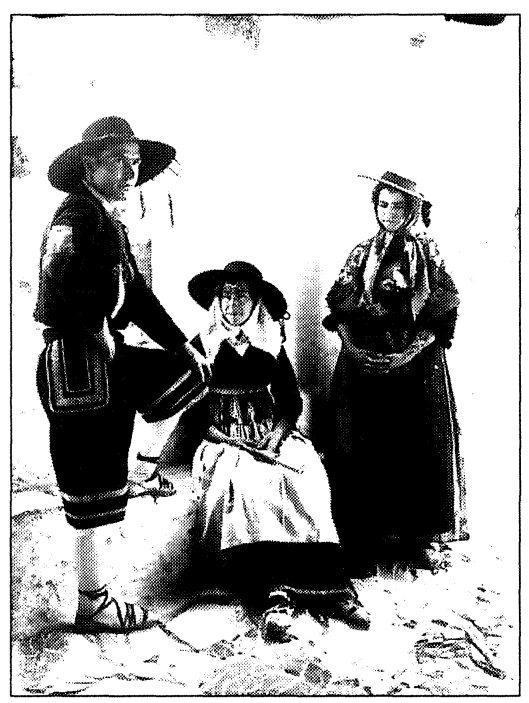

Fig. 2.-Fotografía de la Escuela Madrileña de Cerámica, Santa Eulalia, 1933. 


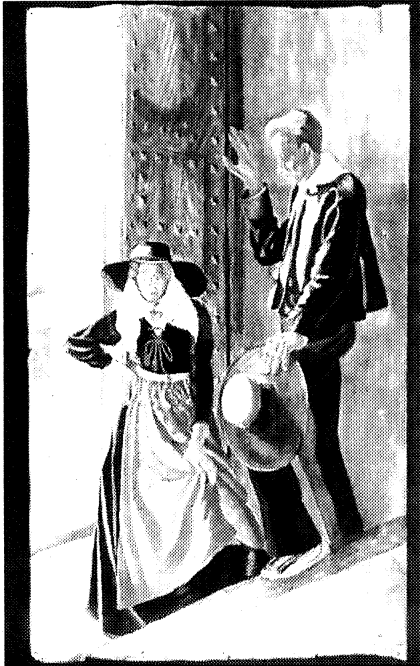

FIG. 3.-Acuarela de la Escuela Madrileña de Cerámica. M. Martínez, 1933 (Foto E.M.C.) bros de la Escuela Madrileña de Cerámica, que en ese año eligieron la localidad ibicenca de Santa Eulària como sede de su curso estival, dado el interés etnológico de la isla.

No obstante, la vigencia de dicha indumentaria y clauer no se habría mantenido hasta ese momento en particular. Sabemos por Ortiz Echagüe que en el mismo año de 1933 aún existían en la iglesia ibicenca de Sant Antoni de Portmany unas pinturas que habían servido de modelo para la réplica del traje en cuestión, en un intento por recuperar ese legado histórico, de su cultura material ${ }^{1}$. Pinturas de las que se había hecho una concreta reseña en el año $1888^{2}$, dejando aquí a una lado su valoración artística.

La pérdida de esas pinturas se ve parcialmente subsanada con la existencia de otras similares en una de las tablas del púlpito de la iglesia de Sant Josep de sa Talaia (Fig. 4) -también en la ruralía isleña-, pintadas en el año 1763 por José Sánchez de Ocaña ${ }^{3}$.

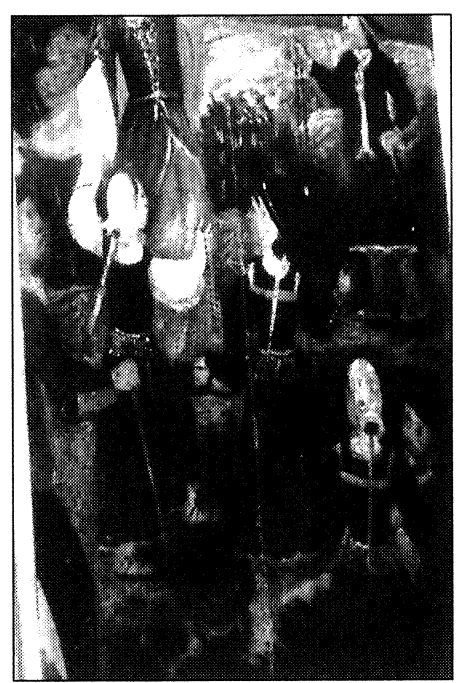

FIG. 4.-Trajes ibicencos del siglo xviII. Fragmento del púlpito de Sant Josep por José Sánchez de Ocaña, 1763 (Foto Domínguez).

1 España. Tipos y trajes (San Sebastián, 1971), XII edición, p. 20.

2 Pablo Piferrer y José M. ${ }^{a}$ QuAdrado, Islas Baleares, en España, sus monumentos y artes - su naturaleza e bistoria (Barcelona: Ed. de Daniel Cortezo y C. ${ }^{\mathrm{a}}$, 1888), p. 1.380. Al reseñar el púlpito de la iglesia de San Antonio se decía lo siguiente: «...la representación de los misterios de dolor en la barandilla del púlpito por inexperto pincel, que en otro pasaje del pedestal, mostrándonos al párroco en actitud de enseñar el catecismo a sus feligreses, dejó curiosa prueba de los trajes usados en aquella fecha de 1769.

3 Joan MARí CARDONA, Sant Antoni de Pormany (Eivissa: Institut d'Estudis Eivissencs, 1985), p. 11. Del mismo autor Illes Pitiüses VI. Portmany (Eivissa: Institut d'Estudis Eivissencs, 1990), pp. 104-105. 
Entre las diferencias reseñables entre unas y otras fuentes iconográficas conservadas, cabe destacar el ligero desplazamiento hacia arriba de la línea de cintura, que se advierte en las correspondientes al presente siglo, mientras las mujeres plasmadas en la pintura de San José, muestran el debido estrangulamiento en el talle.

Según se ha escrito, los colgantes ornamentales que se sujetaban a la cinta de la mujer con una placa en forma de gancho, habrían pasado de moda hacia 1830 , si bien se mantuvieron por más tiempo con carácter meramente utilitario ${ }^{4}$, sin considerar ahora el supuesto mayor arraigo en los estratos llanos de la sociedad.

Este tipo de adorno se ha llegado a considerar la pieza más característica del siglo XVII, la llamada chatelaine; "término que proviene del nombre que se daba, en siglos anteriores, al guardián de un castillo, cuyas llaves pendían de una cadena atada al cinto o cinturón". De acuerdo con ello, "la chatelaine dieciochesca sería también, en principio, una cadena con ganchos para incorporar llaves, aunque se usara principalmente para colgar relojes, sellos, pequeñas bolsas, tijeras", etc. ${ }^{5}$ "Reloj colgado á la cintura" es el que, por ej., alude Puiggarí al referirse a las majas del siglo XVIII ${ }^{6}$.

Retrocediendo al siglo XVII, este mismo autor afirma que en los estamentos populares españoles las mujeres ya lucían "ceñidor de plata, ó cordón de seda salteado de placas de argentería, cinceladas y esmaltadas las del centro, siendo gloria de cada doncella colgarse 30 ó 40 escudos de plata al cinturón, sin perjuicio de la cadenilla que sostenía tijeras, llaves, bolsa y cuchillo..." ${ }^{7}$. En su opinión, los llaveros y otros adminículos por el estilo" eran ya por entonces "de uso general" ${ }^{8}$.

En conformidad con todo ello, a lo largo de estas dos centurias los protocolos ibicencos nos han dejado constancia de la gran implantación social de que gozó este conjunto de cinta-cadenó-clauer.

Llegando - en nuestro paseo retrospectivo - al siglo XVI, resultan de singular relieve varias cadenas "para çeñir" con su llavero, que aparecen registradas en el inventario de la recámara de Doña Juana la Loca 9. Así

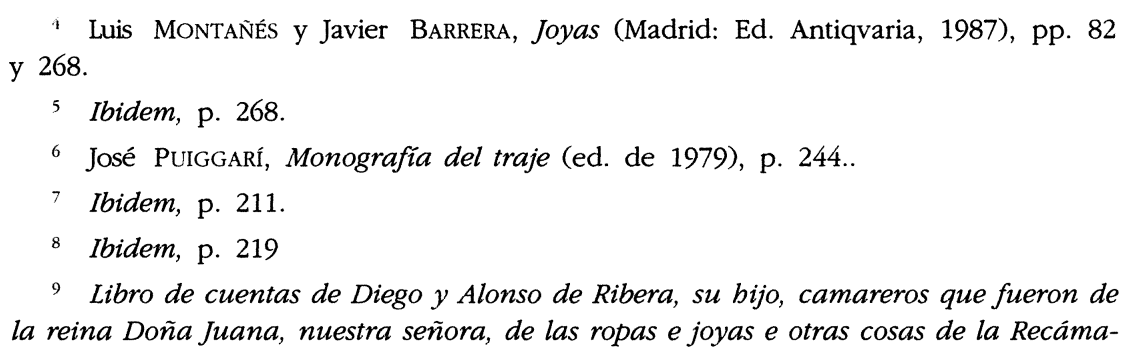


-y por citar un ejemplo en concreto-, entre los distintos bienes que estuvieron a su cargo entre 1509 y 1555 , se cuenta una "cadena de oro fecha a la manera de flandes", "con una poma llena de anbar e su llabero con quatro rramales que tenía çinco llabes, las tres grandes e las dos medianas"; conjunto que alcanzaba un peso total de "quatro marcos e una onça", dejando aparte "Otras quatro llabes que se pudieron quitar al tiempo del pesar". ${ }^{10}$. Otra "cadena de oro para çeñir", también "fecha a la manera de flandes" y "con su llabero" de dicho metal, es la que se describe en este mismo inventario "con dos ramales" y con un peso de "un marco e çinco onças e tres ochabas" $"$.

Sin detenernos en la transcripción de otras citas más o menos similares -igualmente contenidas en este documento real-, es de destacar la similitud descriptiva que se patentiza entre dichos registros y otros posteriores correspondientes a la isla de Ibiza -como veremos más adelante-, salvando la distancia existente entre unos y otros, en función de la mayor riqueza de los que acabamos de reseñar.

A los siglos XV y XIV corresponden, por su parte, otros ejemplos. Entre ellos cabe citar los dos que figuran recogidos en el $D C V B^{12}$, que parecen alejarse tipológicamente de los que aquí tratamos: "Vn clauer de seda blaua clara", ("doc. a. 1412, arx. parr. de Sta. Coloma de Queralt".); "Un corregot de dona ab un clauer de lautó" ("doc. a. 1331, mateix arx").

En el siglo XIII, según Berceo, las llaves colgadas al cinto eran propias de la "muger tocada" o con toca; es decir, de la dueña, casada o señora mayor, siguiendo la transcripción hecha por Puiggarí ${ }^{13}$. Autor que además señala cómo por estos años dicho cinto era, por lo regular, delgado, de correa, paño, o terciopelo, si bien continuaban los cinturones lujosos de oro y plata entre damas y caballeros, "en ocasión de lucimiento y aparato" ${ }^{14}$.

ra de su Alteza que fueron a su cargo desde el año 1509 basta el año 1555, que falleció su Alteza (V. nota siguiente).

10 José FERRANDIS, Datos documentales para la bistoria del arte español. Inventarios reales [Juan II a Juana la Loca] (Madrid: C.S.I.C., Instituto Diego de Velázquez, 1943), p. 185.

11 Ibidem.

12 Diccionari Català, Valencià, Balear (Inventari lexicogràfic de la llengua catalana en totes les seves formes literàries $i$ dialectals, recollides dels documents $i$ textos antics $i$ moderns, $i$ del parlar vivent al Principat de Catalunya, al Regne de Valencia, a les Illes Balears, al departament francès dels Pirineus orientals, a les Valls d'Andorra, al marge oriental d'Aragó $i$ a la ciutat d'Alguer de Sardenya). Obra iniciada per Mn. Antoni M. Alcover. Redac. per Mn. Antoni M. ${ }^{a}$ Alcover $i$ Francesc de B. Moll. 10 vols. (Palma de Mallorca: Ed. Moll, 1988). S.V. CLAVER, CLAUER.

13 José PUIGGarí, Estudios de indumentaria concreta y comparada. Siglos XIII y XIV (Barcelona, 1890), pp. 46 y 95.

14 Ibidem, p. 95. 
Buscando el posible y ya insinuado origen de dichos elementos, sabemos que, a partir de la Edad Media, se denominaba "clavería" a la dignidad de clavero en las Ordenes Militares que tenían en su custodia las llaves y la responsabilidad de la defensa de su principal castillo o convento ${ }^{15}$.

Para esos tiempos, sin embargo, no contamos con pruebas notariales que permitan rastrear el desarrollo e implantación de estas piezas en Ibiza. Tal como se ha señalado, el hecho de que los antiguos escribanos, y sus sucesores los notarios, ejercieran durante siglos su función de fedatarios como actividad de naturaleza privada, explica que, al estar las escrituras en manos de particulares, muchas de éstas se hayan perdido o, en el mejor de los casos, que las conservadas en la isla no se remonten a etapas anteriores al siglo XVII ${ }^{16}$.

\section{ASPECTOS FORMALES}

\section{A) Precedentes atestiguados iconográficamente}

La limitación cronológica de esa fuente documental no hace aquí sino realzar la importancia que reviste la localización de ciertos precedentes iconográficos, más allá del estricto límite insular.

De este modo -y reconstruyendo ya la secuencia cronológica-, podemos señalar algunos ejemplos:

En el retablo de San Esteban, del taller de los Vergós, que se conserva en el Museo de Arte de Cataluña (Barcelona), se puede apreciar la representación de "un ama de llaves" del siglo $\mathrm{XV}$, que dormita junto a la cuna de un niño, con las llaves pendiendo desde su cintura sobre la gonela o saya ${ }^{17}$ (Fig. 5).

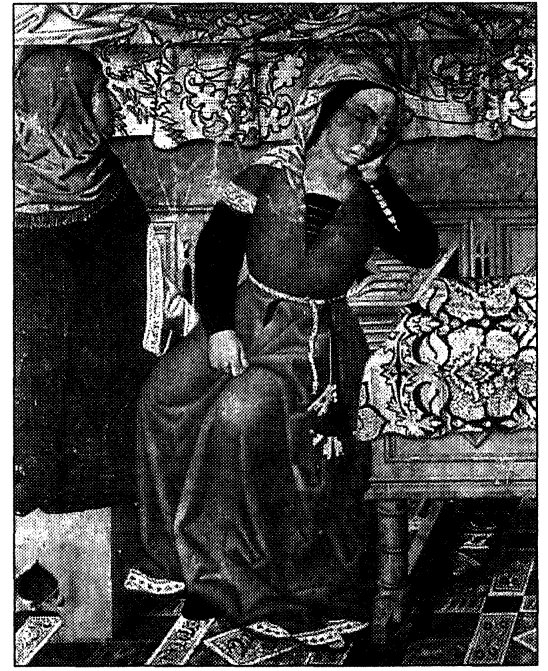

Fig. 5.-Mujer con toca, gonella y clauer. Retablo de San Esteban, taller de los Vergós, siglo Xv (Museo de Arte de Cataluña).

15 Francisco GaRCía GaRCía, La llave: evolución artística y valores de representación simbólica (Murcia: Univ. Murcia, 1992), p. 247.

16 Bartolomé ESCANDELl BONET, Ibiza y Formentera en la Corona de Aragón (Mallorca: Ed. El Tall, 1994) Tomo I, p. 81.

17 Marqués de Lozoya, Historia de España (Barcelona: Salvat, 1975), Tomo III, p. 417. Carmen Bernis MAdRAZO, Trajes y modas en la España de los Reyes Católicos (Madrid: C.S.I.C., Instituto Diego de Velázquez, 1978), Tomo I, Lám. XIII, fig. 23, p. 79. 
En "La mesa de los pecados capitales" del Bosco (1450-1516), y concretamente en "la gula", que puede contemplarse en el Museo del Prado, la mujer que transporta las viandas lleva una llave colgada de esta misma forma, al lado de su faltriquera. Esta llave podría aludir, según F. García García, a "la llave de la despensa en un sentido simbólico", aunque ello no niegue que se trate de una "llave retratada" ${ }^{18}$.

En la "Danza de los campesinos", de Brueghel (1568), conservada en el Kunsthistorisches Museum de Viena, una de las campesinas deja asomar "la llave real de su casa" ${ }^{19}$ entre los pliegues de la saya, también al lado de su faltriquera.

En todos estos ejemplos, sin embargo, no se observa la riqueza que se ha reconocido en varias cintas, o cinturones femeninos, de los siglos XV y $\mathrm{XVI}{ }^{20}$, ni la complejidad ornamental de las llamadas chatelaines, tal como parece desprenderse de muchos de los registros de cintes-cadenons y clauers, contenidos en la documentación ibicenca de los siglos XVII y XVIII.

\section{B) Conjuntos documentados en Ibiza}

Dejando aparte la distinción entre "cintas cortas" y "cintas de caída" - de la que no hemos hallado testimonio escrito en Ibiza, de forma expresa-, conviene advertir sobre la ambigüedad de los términos manejados. En este sentido, del mismo modo que las voces de cinta y cadenó podían ser equívocas (refiriéndose ambas -independiente o globalmente-, tanto a la cinta de plata que envolvía la cintura, como al tramo de cadena que bajaba por un lado del faldar y del que pendía el clauer propiamente dicho), bajo la de clauer tanto podía entenderse ese tramo o tramos de cadena, como, genéricamente, todo el conjunto... Acerca de su conformación, nos sirve de temprano ejemplo un informe de los años veinte del siglo XVII, obtenido en el Archivo de Protocolos de Ibiza (API): (API, Bermeu, 1625-1628, f. 210): "Un Clauer de Argent ab dos camas i en cada cama te trenta quatre baulas y lo demes te cinquanta quatre baulas a mes de les quatre baulas grans y dos caps lo qual clauer te les baules sensilles y romput en quatre parts".

Sobre la cantidad de plata utilizada en la elaboración de este tipo de joyas resulta también especialmente ilustrativo un informe de finales de esta mis-

18 Francisco García García, op. cit. en nota 15 (1992), p. 24.

19 Ibidem.

20 Carmen BERNIS MADRAzO, Indumentaria española en tiempos de Carlos $V$ (Madrid: C.S.I.C., Instituto Diego de Velázquez, 1962), p. 84. 
ma centuria: (API, Hervàs, 1693, ff. 192v-193): "un Cadenó de sis Reals de Vuit ${ }^{21}$ de plata el qual se fara de aquelles divuit peses de vuit ${ }^{22}$ que em deu lo onorable Pere Bofi de Toni Torrentw; "qtó. ${ }^{23}$ del Pla de Vilaw.

A este registro se suman otros de similares características, en los que se precisa el peso consiguiente. (API, Tur Riera, 1703, f. 37v): “Un Clauer del pes de set peses de vuit; Inventario de los bienes de aLluqui Tur de Lluqui, mariner". (API, Ximeno 4, 1716, f. 142): “Un Cadenó de plata que pesa vuit pesas de vuit y mitja, $\mathrm{y}$ altre que pesa sinch pessas de vuit $=$ Item dos Clauers, un que pesa quatre pesas de vuit, y lo altre tres"; "quartó de Balansat y lloch de Rubión. (API, Ximeno 4, 1716, f. 205v): "un cadenó q. pesa vuit ps. de 8 y mitga $=$ Item un Clauer q. pesa sinch pesas de 8 y mitga"; "quartó del Pla de Vila, mayoral de la Torre de Cassa en Riambau..

Tanto a finales del siglo XvII como a comienzos del XVIII los cadenons inventariados en Ibiza generalmente estaban hechos con eslabones o baules de forma circular. Algunas veces, como ya hemos visto en el ejemplo que abría la serie, se precisa el número de dichas baules o peces.

Este es el caso, nuevamente, del "cadenó doble baula redona", con 169 piezas que se registra en 1691 junto con otro también de "baula redona" y más sencillo, de 209 eslabones, igualmente "entre ganxo i bellota" (API, Hervàs, f. 232v)". Del primero de ellos colgaría el clauer que los acompañaba, de dos ramales o "camas", "baula de cadena", y 62 "baulas eo pesas" (ibidem).

El tamaño de las baules se subraya en un informe de 1693 (API, Hervàs, f. 122v-123) relativo a un clauer y un cadenó de plata, "de baula redona grosa"...

${ }^{21}$ Real o reial de vuit: "moneda imaginària que valia quatre pessetes". V. "Reial" en el $D C V B$ (V. Nota 12).

22 "Peça de vuit: moneda de quatre pessetes (Eiv.)". La pesseta, por su parte, "quan era d'argent pesava 5 grams" ( $D C V B$, reseñado en la Nota 12).

23 La "reconquista cristiana" de Ibiza y Formentera llevada a cabo en el siglo XIII por G. de Montgrí (Arzobispo electo de Tarragona), por el infante don Pedro de Portugal ("señor del reino de Mallorca»), y por don Nuño Sanz (Conde de Rosellón), supuso una división y un reparto del territorio insular entre los conquistadores. Limitándonos a la isla de Ibiza, de la Villa y Fortaleza se hizo una división tripartita, situando en el alfoz (Llano de la Villa) el emplazamiento del patrimonio asignado como dotación de la nueva Parroquia de Santa María, y dividiendo dicho alfoz a su vez en tres partes. El resto de la isla se dividió en cuatro "porciones", repartidas proporcionalmente según el contingente militar aportado por cada uno de ellos. Dichas "partes" o "partidas" - posteriormente denominadas "quartons"-, eran: Santa Eularia, Balansat, Portmany y les Salines. Todo ello supuso el reajuste de los cinco distritos en que se dividía la Yabisa musulmana (Xarc=el oriente, Bani Samid, Burtu Mani y Al-Garb, sur), lo que trajo consigo que el quinto de esos distritos, Al-hawz (=alfoz), continuara teniendo cierta vigencia entre los cristianos, quienes lo llamaron "quartó del Pla de Vila». 
En el año 1729 constatamos por primera vez la baula cairada en un clauer de 87 piezas (API, J. Rosell, f. 121v). Y en 1763 vemos como ya se considera antigua la de tipo circular o "redona" que identificamos en una cinta (API, J. Sala, f. 95v)".

A este mismo año pertenece otra "sinta de Plata, arrason de treinta y sinco libras y un sueldo la onsa" ${ }^{24}$ que, pesada por el platero, había "pesado trescientas quarenta una libras sinco sueldos" (ibidem, f. 50).

También a 1763 corresponde el registro de un "llaverito a la mallorquina", inventariado junto con "una sinta Baula menuda con un relicario" (ibid., f. 102v), tal como ya hemos expuesto en otras ocasiones ${ }^{25}$.

Los informes contenidos en la documentación notarial nos ilustran igualmente sobre los demás elementos que podían estar presentes en esta manifestación ornamental: (API, A. Arabí, 1710, f. 98: “Un Cadenó de 180 baulas ab un canonet (¿alfiletero?) y una ballota q. pesa segons diuen Cinch reals de Vuit"; "Quartó de Sta. Eulalia". (API, Ximeno núm. 4, 1.715, f. 65): "un clauer de plata $a b$ tres carres ab una ¿rosa? es mig y quatre claus de ferro"; "Quartó de Sta. Eularia". (API, J. Rosell, 1729, f. 100v: "una sinta de Plata baula redonda, con su Abellota, Plancha y Garfio con ducientas baulas"; "quartón de Balansad". (API, J. Rosell, 1729, f. 103v: "una sinta pequeña baula menuda, con su Abellota y Pechina vulgo escupina de Plata"; "quartón de Santa eularia". (API, J. Sala, 1763, fol. 100v: "una sinta de Plata baula redonda, con su Abellota, Plancha y Garfio, con ducientas baulas"; "quartón de Balansad"...

Sin embargo, ninguno de los documentos estudiados nos permite reconocer para las "abellotas", "ballotas" o "bellotas" una funcionalidad explícita, como la de contener esencias o aromas - recogida en el $D C V B-$, o la de servir de estuche de reloj, como sabemos que ocurría con la "vellota" que perteneciera a D. ${ }^{a}$ M. $^{a}$ Bárbara de Braganza ${ }^{26}$. Piezas a las que po-

21 En el siglo XVIII Ibiza perdió muchas de sus peculiaridades y entró en la uniformidad política de los Borbones; uniformidad en la que se incluyó el idioma. "La llengua catalana s'intenta desterrar, sia amb disposicions probibitives sia amb l'exemple d'autoritats, església $i$ classes dirigents, $i$ per aquest temps desapareix, en efecte, dels documents oficials". Marià VILLANGÓmEZ LLOBET, Eivissa. La terra, la bistoria, la gent (Barcelona: Biblioteca Selecta, 1974), vol. 479, pp. 87 y 92.

25 M. ${ }^{a}$ Lena MATEU PRATS, "El traje en Ibiza durante el siglo XVIII. Variantes de la 'gonella de burell' y los 'calçons de negrilla'n, Conferencia Internacional de Indumentaria (Madrid: Ministerio de Cultura, ICOM-Museo Nacional del Pueblo Español, 1993), pp. 229-236. M. a Lena MATEU PRATS, "La gonella de burell i clauer al llarg dels segles XVII i XVIII", Rev. Eivissa, núm. 24, 3. ${ }^{a}$ época (Eivissa: Institut d'Estudis Eivissencs, 1993), pp. 26 (482)-32 (492).

26 Archivo General de Simancas. Gracia y Justicia, Leg. 923; 1759; Guadalupe RAmOS DE CASTRO, «La influencia de Portugal en la orfebrería española: las joyas", Relaciones 
dríamos sumar algunas otras, aunque no presenten esta nomenclatura específica. Estamos pensando, por ejemplo, en la "poma llena de anbar" que señalábamos al tratar las "cadenas para çeñir con su llabero", de D. a Juana la Loca.

En otras ocasiones, contamos con muestras de "persintas", registradas a veces como "moriscas" (API, J. Sala, 1763, f. 102v; R. Oliver y Castelló, 1786 , f. 197v), o ateniéndose a su conformación. Este es el caso de la que se describe "de seda buena con cinco Duros de Plata y quatro Doblones de veinte dos de cuño viejo, y los otros de cuño nuevon (API, R. Oliver y Castelló, 1786, f. 11). Informe, este último, que nos permite recordar el cordón de seda salteado de placas de argentería aludido por Puiggarí, y del que podían colgar 30 ó 40 escudos de plata, "sin perjuicio de la cadenilla que sostenía tijeras, llaves", etc., tal como ya recogíamos en la introducción ${ }^{27}$.

En lo que respecta a las percintes moriscas ¿podríamos, tal vez, identificarlas con las que hallamos representadas con caireles o flecos en el mencionado púlpito de San José, y que han venido caracterizando ese llamado "traje de clauer ${ }^{28}$ Es decir, las mismas que creemos haber reconocido también en los documentos, gráfica y sencillamente, bajo las voces de "Cordones" o "Cordoneras" (Ej.: API, J. Sala, f. 169v: "una Basquiña de Borel buena con dies y nueve cordones vulgo cordoneras de seda"..., "otra Basquiña de borel vieja con dose cordones de seda") ${ }^{29}$.

Acerca de la aludida imprecisión en la nomenclatura utilizada para referirse a las cintas de plata y/o cadenons, resultan especialmente ilus-

artísticas entre Portugal y España, coord. por Jesús M. ${ }^{2}$ CAAMAÑo, Col. Estudios de Arte núm. 1 (Junta de Castila y León, Consejería de Educación y Cultura), p. 209.

27 Este autor, también alude un cinto (persent) p. ${ }^{a}$ moneda, al tratar el siglo XIV, op. cit. en Nota 13 (1890), p. 235.

28 Entre las guarniciones moriscas figura la de los caireles, o "guarnición que queda colgando a los extremos de algunas ropas a modo de fleco" (Dic. de la Lengua). No solo es fácil encontrar en nuestras artes figurativas personajes vestidos intencionadamente a la morisca, luciendo gruesos flecos en trajes y tocados, sino que además es frecuente que tuvieran flecos y caireles muchas de las prendas moriscas que describen los textos. Carmen BERNIS MADRAZO, "Indumentaria española del siglo XV", Archivo Español de Arte, XXX (1957), pp. 187-209.

Dejamos aquí aparte la relación de los "ceñideros" con las tocas moriscas. Carmen BERnIS MADRAZO, op. cit. en Nota 17 (1978), Tomo II, p. 78. Relación que quizás hay que tener especialmente en cuenta al tratar las fajas masculinas del hombre ibicenco, conocidas en la isla como "tocas".

29 Las voces de "cordoneras" O "Cordonaduras" y de "cayreles" aparecen citadas entre los "accesorios de vestidos y ropas" documentados ya en el siglo XIV. José PuIGGARí, op. cit. en Nota 13 (1890), p. 322. 

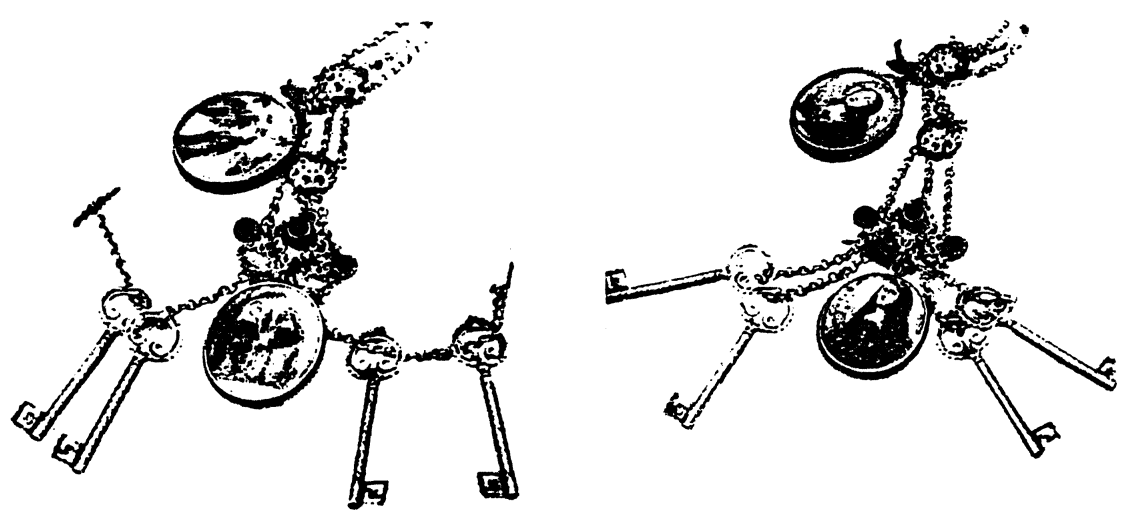

FIGs. 6 y 7.-Único clauer-testigo que se conoce en Ibiza, procedente de can Xesc Nebot (Benimussa, Sant Josep). Foto J. Marí Tur.

trativos dos informes del siglo XVIII: (API, J. Sala, 1763, f. 212: "una sinta y un cadenon de Plata con dos llaves de Platam. API, R. Oliver y Castelló, 1786, f. 112v: "tres cintas vulgo cadenons de plata y un llavero....).

La aparición de un relicario en estos conjuntos - que ya veíamos en el año 1763 con la "sinta de Baula menuda" que acompañaba al referido "llaverito a la mallorquina" (API, J. Sala, fol. 102v)—, se hace frecuente a partir del último cuarto de esa centuria dieciochesca. Tenemos así constancia de ejemplares con "un relicario en dos vidrios, de plata" (API, J. Sala, 1776, f. 13v) o una "joia (API, R. Oliver y Castelló, 1786, f. 10v), descrita la mayoría de las veces como de plata (id. ff. 19, 96v, 112v, 131, 248), o bien de cristal (ibid., f. 59)...

Ya a principios del siglo XIX corresponden otros dos llaveros, con dos $\mathrm{y}$ tres agnus, respectivamente, todo de plata (API, V. Gotarredona, 1.803, ff. 59 y $94 \mathrm{v}$ ), que constituyen un puente entre los anteriores ejemplos y los clauers de los que nos han llegado testimonios fotográficos: El que aparece en la referida postal con que iniciábamos este estudio, y el que constituye la única pieza-testigo conocida en la actualidad (Figs. 6 y 7). Fotografías, ambas, que parecen haber captado un mismo ejemplar.

En estos dos últimos casos - y especialmente en el de la pieza-testigo-, podemos advertir que se trata de relicarios en dos vidrios, o joies, ateniéndonos a la nomenclatura isleña. Según se ha escrito, de las dos joies de plata que presenta esa pieza-testigo, la primera muestra en el anverso la representación pintada de la Virgen de los Dolores, y en el reverso la de la Sagrada Familia; ambas escenas con predominio de los colores rojo y azul. En la otra joia -que comparte los mismos colores-, el anverso lo ocupa la figura de un Evangelista - probablemente 
San Juan-, y el reverso la Coronación de la Virgen María. Tanto una como otra joia tienen una longitud de $7 \mathrm{cms}$., y una anchura de 6,30. La largura del clauer - sense comptar el cinturó ja perdut però que també era de cadeneta de plata- es de $44 \mathrm{cms} .{ }^{30}$

Los elementos metálicos que constituyen el extremo de las cames de dicho clauer, y que hallamos dispuestos transversalmente a modo de muletillas, tendrían la función de atravesar algunos de los orificios con que cuenta al respecto el motivo ornamental que los acompaña (¿rosan?), cerrando en círculo ese tramo de cadena o cama, y configurando así el soporte de las llaves; es decir, el llavero propiamente dicho.

\section{C) Paralelismos con las islas de Mallorca y Menorca}

Dentro del archipiélago balear - sin contar aquellos otros paralelismos localizables en el resto del territorio español-, las islas de Mallorca y Menorca nos proporcionan significativos datos comparativos con el tipo de ornamento que estamos tratando.

El uso de tales adornos en Mallorca se desvela a través de la prohibición, fechada hacia 1565, de aportar [...] trena ne cordó de or, argent de fil ne de martell de la cinta en avall, acceptat o exceptat -según las distintas transcripciones- cadenó, clabuer y penitencia ab senyals de $o r^{31}$.

Bastante posterior es un texto de J. Ramis y Ramis, Asesor de la Comandancia General de la isla de Menorca, en el que se refieren "Los adornos de la cintura" que por el año de 1786 portaban allí "las Mugeres ricas", y que consistían "en un relox, ó una cadena con un pendiente todo de oro; y en las de menos conveniencias en una cadena ó llavero de plata" ${ }^{32}$.

Igualmente, cuando el Padre Colom, en un manuscrito de principios del siglo XIX, coteja el vestir que por entonces llevaban las mallorquinas, con el que lucían en tiempos pasados, afirma sobre las "antiguas" que solo

30 Joan MARÍ TUR, "El clauer i l'adreç, dues peces de l'orfebreria popular eivissenca", Eivissa, núm. 2 de la 3." época (1973), pp. 6 (46)-7 (47).

31 Cita recogida en el $D C V B(\mathrm{~V}$. Nota 12), en las voces de cadenó y claver o clauer, donde respectivamente se ofrece como fuente manejada la Historia de Sóller de José Rullán (Palma de Mallorca, 1875-76), Tomo I, p. 861 y el Bolletí de la Sociedat Arqueològica Luliana (III, -11).

32 Andrés Murillo Tuduri y Luis Plantalamor MassaneT, "Descripción del traje típico menorquín de fines del siglo XVIII, según manuscrito de D. Juan Ramis y Ramis" (Zaragoza: III CNACP, 1979) pp. 499-508. 
las ricas se ceñían con "cinta de or", mientras las menestralas "traían cinta de plata" 33 .

En consecuencia, como perteneciente a este último estamento social tendríamos ya en principio que considerar a la referida cinta de plata y baula menuda que se inventarió en Ibiza en 1763, junto con el susodicho "llaverito a la mallorquina con quatro llaves de Plata" (API, J. Sala, f. 102v). El hecho de que el tamaño de los eslabones de esa cinta sea menor que el habitual en Ibiza, junto al diminutivo aplicado al clauer, parece indicarnos una diferenciación entre ambas islas, a la vez que una íntima relación.

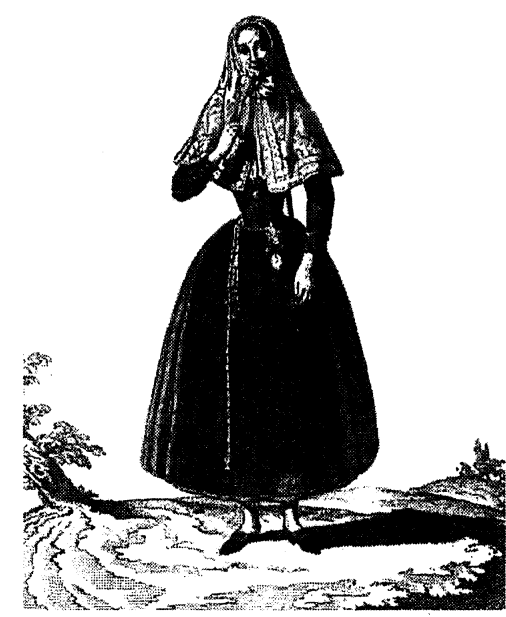

FIG. 8.-Señora mallorquina con claueret y reloj. Ant. ${ }^{\circ}$ Carnicero, dib., y J. de la Cruz Cano y Holmedilla, grab., 1777.
Por su parte, en el dibujo que hiciera Antonio Carnicero de una "señora mallorquina", y que Juan de la Cruz editara en forma de grabado en el último tercio del siglo XVIII ${ }^{34}$, dicha dama "lleva prendida de la cintura una cadena de oro que cae sobre el delantal en doble y sencillo y de la que cuelgan dos llaves" (Fig. 8), siguiendo la descripción hecha por A. Mulet en un estudio específico ${ }^{35}$. "Además - prosigue-, prendido de la misma cadena $y$ en la misma cintura se ve un joyel sujetador del reloj que venía a ser también una joya. A esta cadena - puntualiza - se la solía llamar precinto, precursor del cordoncillo ${ }^{36}$, que en varias vías se sujetaba al cuello y aun daba varias vueltas a la cintura y que para ser completo debía medir 16 palmos" (V. Nota 39).

33 Antonio Mulet, El traje en Mallorca (Palma de Mallorca, 1954), pp. 46-48.

34 Juan de la CRUZ CANO Y Holmedilla, Colección de trajes de España tanto antiguos como modernos que comprebende todos los de sus Dominios, Dividida en dos Volúmenes con ocho quadernos de doze estampas cada uno. Dispuesta y grabada por $D$. Juan de la Cruz Cano y Holmedilla (Madrid: Casa de M. Copín, 1777).

35 Antonio MULET, "El traje balear en doce láminas del siglo XVIII, Panorama Balear, Monografías de arte, vida, literatura y paisaje dirigidas por Luis RIPOLL ARBOS, núm. 2 (Palma de Mallorca, 1951) p. 9.

36 Este mismo autor en un estudio de 1954 (V. Nota 32, p. 39), al comentar el retrato al óleo de la joven F. Barceló, realizado alrededor de 1798, señala la "presentación del cordoncillo de oro", como propia de esta época. 
Ampliando este comentario con el de otros varios autores, se observa cómo en la isla de Mallorca las mujeres ciñeron su cintura con la cinta, cordoncillo o cadena de oro o plata, que asimismo bajaba por un lado del faldar, y en cuyo extremo figuraba un relicario, o una cruz (generalmente de Malta), o las llaves y una campanilla, como símbolos prácticos de su señorial posesión del hogar ${ }^{37}$.

En todo caso, hay que hacer constar que no solo de la cintura pudieron pender estos objetos, sino también del propio cuello, colgando de una gargantilla ${ }^{38}$; modalidad que hallamos reflejada en un documento reproducido en el $D C V B$, referente a una via (V. ibid.) o cadeneta per adornar el coll. (Alaró), con llaves como extremo: s'al.lota duia una via amb ses claus penjada p'es coll.

Como Cadeneta d'or que les dones de la pagesia duen penjada pel coll (Mall), se define el término castellanizado de cordoncillo en el referido $D C V B$, aunque también pudiera caer sobre el pecho y rodear la cintura, como veíamos anteriormente. Tipo de joya del que Ibiza asimismo nos ofrece representativos ejemplos; alguno de plata (API, Hervàs, 1693, f. 100) y, sobre todo, de oro, especialmente en lo que se refiere a joyas-testigo.

En realidad, y después de lo expuesto hasta el momento, no ofreceríamos una visión real de la joyería en Ibiza si no aludiéramos a la presencia en ella de las joyas de oro. Muy particularmente, aquí, del mencionado cordoncillo, del que tenemos testimonio en el año 1747 , junto con una cruz y perlas (API, J. Sala, f. 25), en La Marina (el barrio portuario de la ciudad de Ibiza), donde aún pervive el recuerdo de su asociación con abanicos o ventalls. Modalidad ésta a "uso de ciudadanas" que enlaza con el de los relojes masculinos, pendientes de una cadena sobre el chaleco...

De 1786 data otro cordoncillo de oro vinculado con una joia del mismo metal, en el "Quartón de Santa Eulalia" (API, R. Oliver y Castelló, 1786, f. 19). Tipo de cadena —al menos actualmente de eslabones alentejuelados-, que ha llegado fosilizado a nuestros días participando en la configuración de la popular emprendada de oro, dispuesto en sucesivas ondas concéntricas sobre el pecho de las al.lotes de la campiña. Es decir, sin mostrar relación con el tipo de joyas de cintura a que aquí nos estamos refiriendo.

37 Nieves de HOYOS SANCHO, "Folklore indumental de España", RDTP, I, (1944), p. 16. Antonio MULET, "El traje mallorquín a través del pintor costumbrista Gabriel Reinés". Separata del Bol. de la Sociedad Arqueológica Luliana, números 716-721 (1947), p. 11. ORTIZ ECHAGÜE, op. cit. en Nota 1, p. 20.

38 Luis MONTAÑÉs y Javier BARRERA, op. cit. en Nota 4 (1987), p. 269. 


\section{ASPECTOS SOCIALES}

\section{A) Las joyas como dote y legítima}

Es un hecho reconocido en el costumbrismo ibicenco el que las joyas hayan venido formando parte de la dote, utilizándose en ocasiones como pago de la legítima herencia, para evitar la parcelación de las fincas en provecho del bereu, o bereus ${ }^{39}$.

Eligiendo al respecto algunos ejemplos representativos, vemos en primer lugar cómo a finales del siglo XVII, en las últimas voluntades de un labrador del "qtó. de Balançat y lloch de Malafogasa", se deja en legado a "Ysabet Serra donzella", hija "llegitima y Natural" del testamentario y de su esposa, "tres centas lliuras p. son adot", a pagar de la siguiente manera: "Cent lliuras a fas de altar ab Robes, Joyes y polices y les Restants doscentas lliuras de Vint lliuras en Vint lliuras de paga cascun any fins sian pagadas" (API, Hervàs, 1691, f. 223)

$\mathrm{Al}$ año 1703 corresponde, por su parte, el testamento de "Pere Riera de Pere, hab. del qtó. de Sta. Eularia", en el que lega a su hija, "Cathalina Riera de Pere", "doscentes lliures dines a fas del altar," pagadas por sus "hereus" (sus hijos Pedro y Antonio Riera), "declarant que sempre que vulla el clauer y Cadenó a conte de son dot que no la pugan impedir ni llevar..." (API, Tur Riera, 1703, ff. 12v-17).

No fue raro que en los legados testamentarios se hiciera recaer en el bereu la obligación de procurar ropas y joyas a sus hermanas, cuando éstas se dispusieran a contraer estado. De esta obligación son un claro ejemplo las últimas voluntades de una vecina del "qutón. de Pormañi" o Portmany, y "lugar del pla", estipuladas en el año 1747 (API, J. Sala, fols. 88-88v). Esta mujer nombraba heredera universal de sus propios bienes a su hija María Planells, si ésta renunciaba a sus derechos sobre los paternos, a favor del hijo varón. En el caso de no "admitir aquella" esta condición, nombraba heredero universal y general de sus bienes al referido

39 Víctor NAVARro, Costumbres en las Pithiusas; Memoria que obtuvo el quinto premio en el primer concurso especial sobre Derecho consuetudinario y economía popular, abierto por la Real Academia de Ciencia Morales y Políticas para el año de 1897 (Madrid: Imprenta del Asilo de Huérfanos del Sagrado Corazón de Jesús, 1901), p. 140. Isidoro MACABICH y Manuel SORÁ, anotaciones inéditas cedidas amablemente por las sras. Bonet Torres, para quienes fueron realizadas. La misma intencionalidad de no fraccionar las fincas se constata en Mallorca con la entrega a las hijas del "cordoncillo", cuya usual extensión de 16 palmos parece ser que equivalía allí a unos 7.000 metros cuadrados de tierra. M. ${ }^{a}$ Lena MATeu Prats, La joyería ibicenca (Palma de Mallorca: Institut d'Estudis Baleàrics, 1984), p. 156. 
hijo Pedro Planells, quien tendría únicamente la obligación "de haver de dar a la antedha hija por Dro. de institucion quinientas libs. Vn., pagadas en ropas, Joias y Dinero quando tomara estado", o sería "de su Dro" ${ }^{40}$. En caso contrario, si la hija accedía a su voluntad, Pedro Planells tendría que vestirla en ese momento "de Basquiña de Borel con cordones de seda, camisa delgada, Delantal asul, sombrero, Mariol, filempua, mangas, espargatas, todo nuevo, y una cinta de plata" que no costara menos de cien libras.

Al mismo año de 1747 pertenece el testamento de otra "vesina y moradora" de la "Ysla de Yviza y en el qutón. de Pormañin, llamada "Ysabel Riera de Nicolás" (API, J. Sala, 1747, f. 229). Mujer ésta que legaba y mandaba a su hija Esperanza, "por el dro. de institucion", "la sinta de Plata" que aquella ya tenía en su poder. "De todo lo qual" la nombraba heredera suya particular.

Igualmente por "Derecho de institución", "Juan Torres de Guillermo Ribas", labrador en "el quartón de las Salinas" y "maioral de la Asienda dicha es clot", legaba en 1763 a cada una de sus hijas "mil libras vellón, una sinta y un llavero con llaves de Plata", "pagaderas cuando tomaran estado", o sería de su derecho. De lo que a su vez las instituía herederas suyas particulares (API, J. Sala, f. 164v).

Correspondiente al último cuarto del siglo xviII y al cuartón de Santa Eulalia es otro testamento por el que se legaban a tres de los hijos, de nombre "Jayme, Miguel y Cathalina Guasch", "quatro cientas Libras vellón a cada uno", "aventaxando al dicho Jayme en dos savanas buenas", y precisando que a la hija se le pagara la mitad con "una sinta de plata" de su pertenencia. "Caso de no darle dicho cadenón", la deberían pagar las "otras ducientas libras" (API, J. Sala, 1776, f. 91).

De 1776 son también las últimas disposiciones de "Cathalina Mari de Cosme, Viuda de Pedro Yern, de serca Perella, venta de Arabí de Santa Eulalia", quien, "usando de las facultades" que su marido la dejó, legaba a su hija "Cathalina Yern de Pedro", "mil y quinientas libras con mas la sinta y

40 M. ${ }^{a}$ Lena MATEu Prats, op. cit. en Nota 25 ("El traje en Ibiza...", 1993), p. 231. "Es práctica bastante observada -dice V. NAVArro (op. cit. en Nota 39, 1901), p. 146-, y muchas veces condición expresa establecida por los donantes, que los legitimarios no pidan su porción mientras vivan en compañía del hereu obligado á dársela; y esta cláusula no falta nunca cuando hay al tiempo del contrato (V. Nota 48) hijas solteras; pues para el caso de que continuasen en tal estado á la muerte del donante, éste deja dispuesto que 'mientras no reclamen su legítima, han de vivir en la casa y compañía del donatario, quien les entregará una babitación decente que cierre con llave, y les permitirá la entrada y uso en el porche, horno y cocina, y aprovechamiento en el pozo ó cisterna' cuando lo hay. Asimismo se les concede 'coger fruta fresca de los árboles'”. 
llavero de plata, y collar de coral, por su dote paterno y materno". Con cuyo legado la hacía asimismo heredera suya particular (API, J. Sala, 1776, f. 94).

"Dueña y señora usufructuaria" de los bienes del marido difunto, sería María Prats de José, "de cerca Buscastell", en el cuartón de Portmany, en virtud de la última voluntad de su esposo, siempre que mantuviese su nombre. $\mathrm{Si}$, por el contrario, contraía nuevas nupcias, únicamente debía entregársele "su dote de treinta pesos sensillos, el llavero y cinta de plata, y quince pesos sencillos más" (API, J. Sala, 1776, f. 110v).

El último de los ejemplos aquí recogidos se fecha ya a principios del siglo XIX, y se refiere al testamento de una labradora del pueblo de San Rafael, llamada Margarita Roselló de Bartolomé, que legaba a su hija "las prendas, Llavero, collar, cruz y abroches de oro" (API, V. Gotarredona, 1803, f. $2 v$ ).

\section{B) Entrega de las joyas por el marido a la esposa, o por los suegros a la nuera}

Los documentos notariales ibicencos y las fuentes bibliográficas también evidencian que existió el uso de ceder, o de entregar, éstas y otras joyas, por parte de los suegros a sus nueras. Así al menos ocurre - de modo más o menos circunstancial - en el legado testamentario de "Lluch Torres Blay del qtó. de Balançat y lloch de Besora", quien en el año de 1691 ordenaba y mandaba que le fuera entregado a la mujer de su hijo Juan, el cadenó que el mismo había cambiado con su otra nuera, Juana Riera (API, Hervàs, ff. 210-212).

Este documento no revestiría mayor importancia si no pareciera tener eco en otras noticias posteriores. Concretamente, en la recopilación que hiciera E. Casas Gaspar de las Costumbres españolas de nacimiento, noviazgo, casamiento $y$ muerte ${ }^{41}$, y entre las que figura la entrega de "las llaves de la casa, un candado y una campana de plata", que en Ibiza hacía la suegra a la que pasaba a ser su nuera. Objetos en los que I. Macabich ya creyó reconocer el tradicional clauer $^{42}$.

Otra forma de recibir el clauer sería la que se recoge en un artículo del ibicenco J. Marí Tur ${ }^{43}$. Según se expone, la novia lo recibía nada más

41 Enrique CASAS GASPAR, Costumbres españolas de nacimiento, noviazgo, casamiento $y$ muerte (Madrid, 1947), p. 289.

42 Isidoro MACABICH LlOBET, Historia de Ibiza, Tomo IV. Costumbrismo (Palma de Mallorca: Ed. Daedalus, 1966-67).

43 Joan Marí Tur, op. cit. en Nota 30 (1973), p. 7 (47). 
concluir la ceremonia nupcial de manos del que ya era su esposo; para ello, a éste ultimo se lo había proporcionado su propio padre, antes de celebrarse la boda, con la emotiva advertencia de que nunca se desprendiera de él ${ }^{44}$.

Como observábamos en otra ocasión ${ }^{45}$, cabe suponer que ambos modos de ofrenda estarían en función de una mejor posición social de la familia del joven, muy probablemente bereu, dada la patrilocalidad dominante. Lo normal era que la casada con un bereu pasase a vivir a la casa de sus suegros, el "hogar ancestral del marido", lo que conllevaría esa simbólica cesión del poder doméstico, de forma directa o indirecta, por parte de la suegra a su nuera, la nueva ama.

Tal vez, incluso, esa donación del clauer por parte del novio, o por los progenitores de éste, más o menos directamente, pudo estar mayormente generalizada, extendiéndose a las que se casaban con los hermanos del primogénito, simplemente en función de acceder al dominio de su nuevo hogar.

En este sentido, dicho obsequio sería perfectamente equiparable con el de los anillos de prometida, que, prácticamente, han llegado a cubrir los dedos de las payesas ibicencas, y que, de acuerdo con lo dicho en 1901 por V. Navarro ${ }^{46}$, era el padre del novio el que los regalaba a la al.lota, en el momento de la petición. Al menos ya por entonces, algunos de esos anillos presentaban cortas cadenillas en comba con diminutos colgantes, normalmente en forma de llave y triángulo invertido ó corazón, que se vienen interpretando como la entrega simbólica de éste último y de la llave del nuevo hogar, o bien de la llave que abre su corazón, sin negar el claro contenido erótico.

\footnotetext{
${ }^{44}$ Viene -quizás - aquí a propósito recordar el comentario hecho por PUIGGARí, op. cit. en Nota 27 (1890), p. 240, al tratar los regalos de boda durante el siglo XIV: «Ningún novio ni pariente suyo de ambas partes - dice- podrá hacer dádivas de cantidades ó regalos de joyas; únicamente el novio podrá dar a su desposada, bolsa de 50 sueldos a lo más, cinta de plata de peso once onzas, dos sortijas de á 60 sueldos y guantes"

${ }_{45}$ M. ${ }^{a}$ Lena Mateu Prats, "Joyería popular ibicenca. Una selección de treinta siglos", Joyas \& Joyeros, núm. 40 (Madrid: Ed. Julián Yébenes Guerrero), p. 30.

46 Víctor NAVArRo, op. cit. en Nota 39 (1901), pp. 136-137. Navarro también puntualiza el hecho de no haber visto "ninguna escritura en que se enumerasen las sortijas que el padre del novio ó éste regalan á la futura contrayentè (Id., p. 140). Esta circunstancia es análoga a la que reflejan los documentos manejados por nosotros, tanto en lo que respecta a dichos anillos, como al clauer.
} 


\section{ASPECTOS SIMBÓLICOS}

Ignoramos si la ofrenda de la cinta-cadenó y clauer del recién casado a su cónyuge pudo guardar alguna relación con el escreix. Es decir, con el "aument excreix de la mitat del dot" que en la isla hacía el hombre a su futura esposa, doncella, "per raho de llurs virginitat" ${ }^{47}$, tal como se expresa en unos Espòlits ${ }^{48}$ del año 1703 (API, Tur Riera, ff. 19-19v). Si fuera así, la referida dádiva del clauer "a faz del altar" por parte del marido a su mujer, estaría en clara relación con la de la dote en ropas y joyas que los propios padres, o los bereus de éstos, hacían respectivamente a las hijas o hermanas, igualmente "a faz del altar", cuando éstas contraían matrimonio.

Resulta curioso observar cómo en otros espòlits del año 1712, pactados entre viudos del cuartón de las Salinas (API, Riera, ff. 26-27), consta que, "Margarita Portas, Vidua de Pere Ribas de Ber." ", aportaba "en dot per dot y nom de dot" a su segundo marido "mil seixanta lliuras de contant en tantas robas de lli y llana, un cadeno de arjent de pes de 50 reals y un escut de or"; en las cuales 1.060 libras estaba comprendido "lo creix" que le habían pagado los herederos de su primer esposo.

Ya se sabe que, en atención a la característica de la virginidad, ciertas legislaciones impedían la concesión de escreix a la mujer viuda cuando contraía nuevo matrimonio. Pese a ello, se encuentran casos de escreix otorgado a viudas y a mujeres indotadas ( $D C V B)$. Punto, éste último, que

47 "El Código de las Costumbres de Tortosa define el escreyx ó donación "propter nupcias" diciendo que es todo aquello que el marido promete ó da a la mujer de sus bienes propios, bien al tiempo de celebrar las nupcias, bien después de contraído el matrimonio haciendo vida común". Dicho escreix "debe otorgarse en los Capítulos matrimoniales y en proporción a la cuantía de la doten. Libre de les Costums Generals Scrites de la Insigne Ciutat de Tortosa [...], de finales del siglo XIII, ed de MDXXXIX, reproducida por Bienvenido OLIVER en Historia del Derecho en Cataluña, Mallorca $y$ Valencia (Madrid: Imp. de Miguel Ginesta, 1876-1881), T. IV, pp. 291 y 293. En cuanto a la correlatividad con la dote, el escreix podía ser una cuarta parte, un tercio, o la mitad de la cantidad dotal, según las diferentes leyes consuetudinarias, conforme a lo recogido en el $D C V B$ (V. Nota 12).

48 "Espoli (dial. espòlit): Escriptura que otorguen abans de casar-se els dos futurs esposos, amb llurs pares respectius, prometent aquests als fills el que els deixeran $i$ disposant ja els esposats sobre els infants que puguin tenir (Eiv.), según consta en el DCVB (V. Nota 12). Para el estudio de las instituciones jurídicas ibicencas, consultar de J. COSTA RAMÓN "Derecho Foral ibicenco", Ibiza, 2. ${ }^{a}$ época, núm. 5 (Ibiza: Instituto de Estudios Ibicencos), pp. 17-58. Del mismo autor: "La legislación de Ibiza y Formentera", en Diario de Ibiza, del 5, 12, 19 y 26 de noviembre, y del 3, 10 y 17 de diciembre de 1978. 
podría también explicar que el marido entregara la cinta-cadenó-clauer a aquella al.lota que fueran al matrimonio sin dote, o sin ese legado en particular. ¿Será así fortuita —nos preguntamos- la relación de la percinta de plata con la panxeta verge que se ha reflejado en alguna ocasión? ${ }^{49}$

En todo caso, el gran arraigo de este conjunto de joyas en las costumbres ibicencas, así como sus connotaciones simbólicas, nos llevan a desestimar, o, al menos matizar, aquellos enfoques por los que el ser amujer de llavero" podía suponer "una falta más", tal como aparece en una cita de Franciso de Rojas recogida en el Diccionario de Autoridades ${ }^{50}$.

Aunque en el texto de J. Ramis y Ramis sobre el traje menorquín aludido anteriormente, "la cadena ó llavero de plata" no fuera propio de las mujeres más ricas, sino, por el contrario, de las de "menos conveniencias", una canción popular catalana ${ }^{51}$ nos está sugiriendo que se inscribía bajo el sello de un determinado nivel social, además de revestir el ya comentado simbolismo de poder doméstico, explicable por su aparente y mera función práctica: Mira que fas, Tereseta; / la cabellera t'enganya; / podries esser mestressa, / mestressa de bona casa, / podries dur bon cintó, / cintó, CLAUER i arracades.

En realidad, el clauer parece ser, ante todo, un atributo de la bien casada. Si los ceñidores simbolizan en el hombre el esfuerzo y el trabajo, las llaves, las tijeras y los objetos religiosos que colgaban de la cintura de las mujeres, nos hablan del hogar y de la hacendosidad ${ }^{52}$, además de la formación cristiana.

Sobre el primer aspecto, tenemos constancia de una pieza-testigo equirable al clauer, que, en lugar de éste, presenta como extremo del cadenó unas tijeras de plata. Procede del ya citado barrio portuario de La Marina, en la ciudad de Ibiza, y se trata además de una pieza que nos atañe personalmenate, al haber sido legada por mi propia bisabuela - junto con un dedal de oro- a la "más hacendosa de sus nietas".

i) El mencionado DCVB (V. Nota 12) recoge en la voz PERCINTA: "Cinyell (mall., eiv); cast. cinto, cinturón. Prest serà ma percinta un cordó (Obras en prosa y en verso de D. Tomás Aguiló. Tomo III. Poesías en mallorquín, Poes. 218. Tipogr. Católica Balear, 1883. Palma). Panxeta verge continguda amb sa percinta de plata (G. Maura y Montaner. Aygo-forts, 95. Nova Edició aumentada amb poesies. Tip. J. Tous. Palma, 1913). Dones galanes ab les percintes d'or y perles. (Obres Catalanes, de Miquel S. Oliver. Ilustració Catalana, Tomo I, 239. Barcelona).

50 Francisco de Roxas, Sus Comedias. Abre el ojo. Jorn. I. (En la voz "llavero", del Dic. de Autoridades).

51 Joan AMADES, Folklore en Cataluña. Costumbres (Barcelona, 1969), p. 630.

52 Antonio CEA GuTIÉRrez, "Los trajes de España, códigos apasionantes", Pabellón de España, núm. 7 (Sevilla, 1991), pp. 22-26. 
Sin embargo, tanto en este caso, como en el de las cintas igualmente con tijeras llevadas por las religiosas dedicadas a la enseñanza de labores - por citar otro ejemplo aún más ilustrativo de su generalización-, cabría ver el carácter eminentemente práctico que se ha reconocido para este tipo de piezas, aproximadamente, desde mediados del siglo pasado.

Frente a ello, su fosilización con carácter popular ha quedado también patente en otras zonas de nuestro país. Así ocurre en la del Rebollar, en la provincia de Salamanca, donde las campesinas han venido luciendo complicados cordones colgando de su cintura a lo largo de la saya, de los que pendían igualmente tijeras, entre otros diversos utensilios de labor ${ }^{53}$.

Por otro lado, un gran llavero atado a la cintura es el atributo de una santa que viene a significar la acción, como es el caso de Santa Marta ${ }^{54}$. Atributo que comparte con Santa Isabel, según se aprecia en un cuadro de la Visitación perteneciente a la iglesia de Sequeros (en la salmantina Sierra de Francia), y que hemos tenido oportunidad de observar gracias a la información facilitada por Antonio Cea Gutiérrez.

Finalmente - y a modo de introducción para el siguiente apartado-, no cabe aquí sino recordar algunos de los conceptos expuestos en el siglo XVI por Fray Luis de León, sobre las cualidades que por aquel entonces debía reunir, según él, "La perfecta casada". ¿Para qué fin "ordenó Dios a la mujer, y se la dió por compañia al marido", sino "para que lo que él ganase en los oficios y contrataciones, de fuera, traído a casa, lo tuviese en guarda la mujer y fuese como su llave?". Así las "buenas mujeres" debían ser "guardas de su casa", "pues las hizo Dios para ella sola", debiéndose contentar con "su suerte", "de sus puertas adentro" 55 .

53 Antonio GARCía BOIZA, "Traje del Rebollar", El traje regional salmantino, por Antonio García Boiza y Juan DOMÍnguez BerRueta (Madrid: Espasa Calpe, 1940), p. 22.

5" Juan CANTÓ RUBIO, "Diccionario de símbolos", Símbolos del arte cristiano (Salamanca: Univ. Pontificia, Cátedra "El lenguaje del Arte», 1985), pp. 179 y 183. S.V. Llave (como atributo de las santas Genoveva, Marta de Betania, Petronila...) y Marta y María.

55 Capítulo XVII: "Rodeó todos los rincones de su casa y no comió de balde". (Genève: Editions Ferni), p. 132. Con esta apreciación enlaza el comentario hecho en 1978 por Claudio ALARCO VON PERFALl, Cultura y personalidad en Ibiza (Madrid: Ed. Nacional, 1981), pp. 186-187, cuando alude el "símbolo de prestigio" que en ese momento suponía para la mujer de la campiña ibicenca el permanecer recluida en su hogar (si bien se refiera al ideal de «ama de casa" implantado por la nueva sociedad industrial). 


\section{OTRAS CONSIDERACIONES}

\section{A) Funcionalidad del "Clauer"}

Una vez aludida la correspondencia simbólica de este elemento con el poder y la autoridad, aunque sea a nivel doméstico, puede resultar conveniente enfocar ahora nuestro trabajo desde un punto de vista eminentemente práctico. Desde esta perspectiva, nos sirve de introducción el recordar cómo la responsabilidad de los "claveros de la Universidad" de Salamanca recaía en la seguridad del arca del siglo XV con cinco cerraduras, que se conserva en la Sala de Manuscritos de aquella Biblioteca ${ }^{56}$.

De esta forma, es lógico suponer que en Ibiza las llaves de las caixes, mitjes caixes, caixons, estrades, o artibancs... que también se han documentado en el vacíado de archivo, ocupasen un destacado lugar en el clauer. Las prendas de ajuar doméstico, ropas y joyas que se guardaban en su interior, así como cualquier otro contenido idóneo, estarían bajo el cuidado de la dueña o ama de casa, responsable de su conservación y seguridad.

A este respecto, en un testamento del primer cuarto del siglo XVII, estipulado por J. Sala, originario del llamado "quartó de Pla de Vila" (API, Bermeu, 1620-1623, ff. 214-215), se ordenaba que, inmediatamente tras producirse su fallecimiento, se restituyera a su segunda mujer todo lo que ella le había aportado, o donado, cuando contrajeron matrimonio: “...las quals cosses" debían serle "restituides y tornadas" de la misma manera en que las había recibido, y que eran, a saber, "una caixa de noguer buida y altra caixa de noguer ab les sues robes". "Caixa", en cuestión, de la que "ella mateixa" había tenido siempre "la clau".

Indicativo de la mayor o menor riqueza que pudieron tener esas llaves mobiliarias, es la descripción que reciben en los inventarios y almonedas los muebles correspondientes: Las caixes grandes ó medianeras aab son pany y clau", en alguna ocasión "de rels" y "ab peus de lleó" (API, Bermeu 1614-1619, f. 70), que otras veces aparecen como "genovesas" (ibid., f. $78 \mathrm{v}$ ), ya han merecido la atención en ciertos estudios dedicados a las islas Baleares. Su peculiaridad radicaba en la forma de zarpa de león que presentaban los dos pies delanteros ${ }^{57}$. Mitjes caixes o caixas mitjanseres de

56 A. GAllego De Miguel, Rejería castellana. Salamanca (Madrid, 1963), pp. 30-33.

57 Joan LLABRÉS RAMIS - Jordi VALLESPIR SOLER, Els nostres arts i oficis d'antany, T.V, (Ciutat de Mallorca: Estudis Monogràfics del Museu de La Porciúncula, 1984), p. 146. La supresión de las basas molduradas en favor de las patas en forma de garras 
olivera u olivo, de nogal, ó, simplemente, negras; caixetes blancas; caixes de poll. (chopo, álamo negro), verdes, verdes de pi (pino), ó blancas..., generalmente "ab son pany y clau", son otros de los ejemplos documentados en la isla de Ibiza a lo largo del siglo XvII.

A todo ello se suman algunos caixons, como es el caso de un "caixó mallorquí pintat lo devanter", a su vez "ab son pany y clau" (API, Bermeu, 1614-1619, f. 38). Y hasta algún que otro estrado con cajones, también con llave y cerradura (API, Bermeu, 1.614-1.619, f. 65v; V. estrada en el $D C V B$ ), y varios "artibanqs" o arquibancs (arca y banc), entre los que se cuenta uno con "dos caixons ab una clau", que había pertenecido a un carpintero de la "vila davall" (API, ibid., f. 93)...

Sin detenernos en enumerar la serie de este tipo de muebles reconocida en las centurias siguientes, cabe destacar la arquilla con "San Christobal pintado", que iría provista de la correspondiente cerradura, y que figura en un inventario de Formentera, del año 1788 (API, Tomàs Juan, f. 126$) \ldots{ }^{58}$

En lo concerniente a las llaves del propio casament, o de algunas de las cases, los documentos manejados sólo nos ilustran sobre éstas últimas, al tratar las restricciones en el poder doméstico con que normalmente se salvaguardaban los derechos de la viuda, al quedar viviendo en casa del bereu.

Singularmente explícitas a este respecto son las ultimas voluntades de un labrador del cuartón de Sta. Eulalia, formuladas en el año 1712 (API, Riera, ff. 77-79). Entre otras varias disposiciones, este labrador asignaba a su "carissima y amada muller", mientras mantuviera su nombre, "una Cassa del casamt. per son estar", en este caso la que ella quisiera. Casa de dormir que imaginamos podría ser "tancada en clau", como se precisa en otro testamento semejante del año 1692 (API, Hervás, f. 20). Le otorgaba además, de acuerdo también con lo más generalizado, el derecho de "entrada en la cuina" y que se pudiera servir "de les eines de Cassa, sens empaig ni contradiccion de persona alguna...." "Eines" que no serían sino "Caldera, Cosi, llibrell i morter, tal como se detallaba en otro testamento de 1691 (API, Hervàs, ff. 173-174v).

¿En tales circunstancias - nos preguntamos- dichas viudas seguirían ostentando el clauer, o, por el contrario, lo habrían cedido ya por en-

se documenta en Cataluña durante el siglo xvir, en las arcas de novia que aún mantenían la tipología medieval. M. ${ }^{a}$ Paz AGuILó Alonso, "Mobiliario en el siglo XVII», Mueble español, estrado y dormitorio (Madrid: Dirección General del Patrimonio Cultural, 1990), p. 121.

58 Joan MARÍ CARDONA, Formentera, Illes Pitiüses III (Eivissa: Institut d'Estudis Eivissencs, 1983), p. 128. 
tonces a su nuera, la nueva ama? ${ }^{59}$ ¿Acaso, tanto suegra como nuera, lucían este conjunto de joyas de un modo meramente ornamental, al menos durante el período en que dichas chatelaines estuvieron de moda? ¿Hasta qué punto las connotaciones simbólicas explican el arraigo del clauer en Ibiza?

En realidad, y a pesar de todo lo expuesto en este apartado, ninguno de los documentos vaciados establece una correspondencia directa entre alguna de las llaves referidas - mobiliarias, o del casament-y el clauer. De las que pendían del mismo simplemente se dice en la práctica totalidad de los casos que eran de plata, y, ocasionalmente, de hierro (API, Ximeno n. ${ }^{4}$, 1715, f. 65; API, J. Sala, 1763, f. 189), contando con ejemplares de plata en los que el pequeño tamaño se hace constar de forma expresa (API, J. Sala, 1763, ff. 69v y 169).

\section{B) Modelos indumentarios relacionados con la "cinta-cadenó" y "clauer"}

Sería muy extenso, y nos apartaría del propósito de este estudio, el profundizar en los distintos modelos indumentarios que la documentación notarial ha desvelado emparentados con el conjunto del clauer, o con alguna de sus piezas integrantes. Por este motivo, nos limitamos a ofrecer, de forma somera, algunos de los ejemplos que pueden ser más significativos, y que ilustran además sobre los distintos estratos sociales que hicieron uso de este tipo de adorno.

A la segunda década del siglo XVII pertenecen varios documentos, alguno de ellos de la campiña y otros de la ciudad de Ibiza, que indican una clara correspondencia de los cadenons y clauers con las saboyanas de estameña negra, pese a no excluir la posible relación de esos adornos con las gonelles de diversos tejidos y colores: de mezclilla o mescla verde, de estamenya verde o parda, etc. (API, Bermeu, 1620-1623, ff. 392-393v; API, Bermeu 1625-1628, ff. 112v-113v, 210, 281v-282).

A finales de esta misma centuria, un vestido de mujer conformado por "basquiña y gipó de sal y pebre", inventariado en Dalt Vila junto con "un

59 Refiriéndose a etapas posteriores, Víctor NAVARRO, op. cit., en Nota 39 (1901), p. 144, alega que la madre que quedaba viviendo en compañía del bereu, cedía "si no en todo, en gran parte á la nuera el manejo de la casan, conservando "la suprema dirección", y desprendiéndose del peso de "las faenas más rudas". Desde una perspectiva psicológica, eel temor de la suegra a ser desplazada del centro de las ocupaciones domésticas creaba una serie de hostilidades desfavorables a la expansión de la personalidad de la joven esposa", en opinión de Claudio Alarco VON PERfall, op. cit. en Nota 55 (1981), p. 183. 
sombrero blanch ab veta negra", distintas "engarinas" y otras diversas prendas, viene a demostrar su conexión también con el clauer (API, Hervàs, 1693, f. 83). Aclarando que por sal $i$ pebre se entiende el "color barrejat del cabells quan comença a haver-n'hi de blancs" (DCVB).

De este mismo momento es un inventario de La Marina, con el registro de "un clauer y un cadenó de plata...", así como de dos gonelas, una "negra teñida", y la otra "de camell", con "devantal de estam negre i rebosillo"... (API, Hervàs, 1693, fols. 122v-124). El hecho de que en otros inventarios igualmente de La Marina se repitan las gonelas "de camell" con rebocillo, viene a fortalecer la implantación social de dicho modelo en esta zona portuaria de la ciudad de Ibiza, si bien en dichos casos no vuelve a constatarse su relación con el cadenó y clauer (API, Hervàs, 1692, f. 74; Id. 1693 , f. 149v).

También "de camell" era una de las gonelas que figuran en un inventario de 1692 perteneciente al cuartón de Santa Eulalia, en el que además aparece una gonella de burell, junto a unas "manegas de cordellat blau", un "devantal" del mismo color, "una bosa de portar al costat", y alguna que otra prenda. Gonelas, ambas, que muy bien pudieron complementarse con una "tovaiola" de cabeza, así como con el "cadenó baula redona" y peso "de 5 reals de 8 ", que se guardaba, aparte, en una tercera "caixa de pi" (API, Hervàs, 1692, f. 155).

Con la mención de la gonella de burell no podemos pasar por alto su fuerte grado de representatividad en la payesía ibicenca, y su estrecha unión con el conjunto de joyas a que aquí nos referimos. La humildad de ese género, aparte de obedecer a la propia de los estratos populares, armonizaba con la honestidad de las "bien casadas", de las viudas ${ }^{60}$, e, incluso, de las al.lotes casaderas. En este último aspecto es ilustrativo el registro notarial de un "cosete de Borel de muchachas buenas", que figura en un inventario del cuartón de Santa Eulalia y año de 1763 (API, J. Sala, f. 103).

Dado que en el apartado sobre el contexto social ya hemos ofrecido ejemplo de la presencia conjunta de "basquiña de Borel" y "cinta de plata"

60 El burel se teñía en negro para lutos (aunque con frecuencia se dejaba en su color natural ó se teñía en pers). "Que provecho vos tién vestir este negro paño? / andar avergonzada e con mucho sosaño? / Señora dejad duelo e facet al cabo de año; / Nunca golondrina mejor consejó ogaño. / Jergas por mal señor, burel por mal marido / A caballeros y a dueñas es provechoso vestidon; JUAN RUIZ. M. ${ }^{\text {a Jesús ALfAU }}$ DE Solalinde, Nomenclatura de los tejidos españoles del siglo XIII. Anejo XIX del Boletín de la Real Academia Española (Madrid, 1969), p. 65. V. también Bartomeu MulET RAMIS, Els Teixits a Mallorca. Opuscle editat amb motiu de la aMostra de Teixits Mallorquins" celebrada al Casal de Cultura de la Ciutat de Mallorca els dies 26 de Febrer a 10 de Març de 1979 (Ciutat de Mallorca, 1979), pp. 9-10. 
entre las prendas que debía entregar el bereu a su hermana, cuando ésta contrajera matrimonio, pasamos ahora a exponer algunos de los testimonios en los que esa obligación indumentaria se refiere a la viuda.

De ello tenemos amplia constancia documental en Ibiza desde el siglo XVII. Sirviéndonos tan solo, no obstante, de algunos legados testamentarios del xviII, vemos cómo un labrador del cuartón de Sta. Eulalia dejaba a su bereu la obligación de entregar a la viuda, de tres en tres años - siempre que ésa mantuviese el nombre del difunto-, un vestido de cabeza a pies, configurado por "Capell, manegues de xamellot negre, Gonella de Burell y devantal blau de Mallorca y espardeñes de Canem..." (API, Tur Riera, 1703, f. 21).

Prácticamente las mismas obligaciones serían las que haría recaer en su bereu otro labrador del mismo cuartón, algunos años más tarde (API, Riera, 1712, fol. 78v). Éste, le encomendaba que facilitara a su viuda un "vestit de plor", inmediatamente después de su fallecimiento ${ }^{61}$; luego, transcurridos tres años, y de tres en tres, un vestit enter de cap a peus desde sabates fins a sombrero, camisa, tovayola prima, gonella de estameña, o burell", lo que ella quisiera, "gipó, manegues, devantal, y faldellí de estameña o vayeta", nuevamente lo que ella prefiriera ${ }^{62}$.

A pesar de que en estas últimas disposiciones no se especifica la configuración del vestit de plor, otros documentos venían aportando noticias al respecto desde el primer cuarto del siglo $\mathrm{XVII}^{63}$. Si entonces un

61 En el $D C V B$ (V. Nota 12) por any de plor se entiende "el primer any de viudesa dela dona" (V. plor). Según los datos recogidos por Bienvenido Oliver (op. cit. en Nota 47, el llamado "an de plor (annus lugubris o año de luto) se halla establecido en el citado Código de Tortosa en consideración a la tranquilidad y sosiego que debe disfrutar el cónyuge sobreviviente durante el "año y día" que sigue a la muerte de uno, u otro.

62 Como hemos visto, y tal como constata Víctor NAVARRo en fecha mucho más reciente (1901), las disposiciones testamentarias difieren muy poco de las establecidas en las donaciones (op. cit. en Nota 39), p. 146. Acerca de las mismas, este autor hace el siguiente comentario (Id. p. 145): "Por gran número de casos de que he conocido en virtud de consultas, sé [...] que son frecuentes las rencillas y disgustos entre los nudos propietarios y el usufructuario á titulo de viudez, sobre todo cuando es la madre la supérstite. Entonces, y por más que el usufructo queda reducido á la simple alimentación y el modestísimo vestido, y por de contado á continuar disfrutando de la habitacion, aún así suele hacerse la carga tan pesada para el nudo propietario, que las exigencias de renuncia son cada día más apremiantes, y no siempre en forma persuasiva, sino amenazadora y hasta contundenten.

63 Ya en el siglo XIII sabemos, por ej., que en Tortosa los bereus del marido contraían, entre otras obligaciones, la de proporcionar a la viuda las vestiduras de luto dentro de los tres días siguientes al fallecimiento de aquel. Vestiduras de lana que por entonces consistían allí en capa o manteyl y goneyla, además de cot ab pena para 
testamento del cuartón de las Salinas hablaba simplemente de mantell o manto y savoiana o saboyana (API, Bermeu, 1620-1623, fol. $457 \mathrm{v}$ ), a finales del mismo siglo un informe. del "Q. de Balansat" y "lloch des Puig den ballet" pormenoriza el uso lúgubre de "Mantell, gonella y gipó de estameña, devantal de girasol y sabates" (API, Hervàs, 1690, f. 142v). El hecho de que en 1770 la basquiña de estameña, junto con jubón anascote y zapatos, aún se considerara vestido de luto, nos permite reconocer dicho carácter en los conjuntos análogos de todo este período.

De esta forma, el legado testamentario de "una gonella de estameña negra y el cadenó" que hiciera en 1712 la esposa de un tejedor del cuartón de Santa Eulalia, pero por aquel entonces "habitant en la [...] Real Força de Yvisa" (API, Riera, 1712, f. 220), nos evoca la relación existente a principios del siglo XVII entre las saboyanas y este tipo de joyas, al tiempo que podría desvelar su compatibilidad aún con el luto más riguroso. Por otro lado, sabemos que en el año 1737 una basquiña de damasco con cadenó y clauer formaba parte de una dote (API, J. Oliver, f. 86)...

En todo caso, la representatividad de las gonelles de burell en los usos de la payesía ibicenca parece tener su correspondencia iconográfica en la pintura dieciochesca presente en el púlpito de la iglesia del pueblo de San José, que mencionábamos al iniciar este estudio. Serían dichas gonelles o basquinyes las que se describen en varios documentos del mismo momento, como hemos visto, con 19, 12 o 9 cordones..., "vulgo cordoneras de seda" (API, J. Sala, 1763, ff. 169v y 189); tipo de ornamento de posible raigambre morisca que cabe reconocer en los cordones o flecos que cuelgan de las cintas femeninas allí reproducidas. Gonella de burell, en definitiva, que regularmente formaba parte de la dote junto con la cintacadenó y/o clauer, y cuyo recuerdo ha llegado a nuestros días como el vestido o traje de clauer.

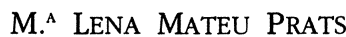

\footnotetext{
el verano, y de saluacors también ab pena para el invierno; todo de daniel o d'aniel (según distintas transcripciones). Durante el referido "an $e$ dia dichos bereus debían asimismo proporcionarle camises, savanes, çabates e calçes. Elan e el dia aquel passat qui es dit "an de plor: les bereus del marit de continent si dins lan e dia no la ban pagada: deuenli fer vestedures, pero qui sien de drap negre...
} 
El clauer, portado tradicionalmente por las ibicencas, es un ejemplo de las joyas que se llevaban colgando desde la cintura. Los Protocolos isleños reflejan la configuración de dicho clauer, y el papel que desempeñaba en los derechos consuetudinarios de dote y herencia. Se analiza su especial relación con la boda, sus connotaciones sociales y simbólicas y su íntima conexión con la indumentaria. A los paralelismos detectados en el archipiélago, se suman otros que ilustran sobre la generalización de este elemento, y su antigüedad, que es posible retrotraer hasta el siglo XIII.

A traditional jewel worn by the women of the island of Ibiza -one of those worn hanging from the waistband-, the clauer appears as a key item in the island's Common Law regarding inheritance and the dowry. Notarial deeds reflect this, and reveal the several elements that enter into the jewel's composition. The author also delves into the clauer's special bearing on traditional clothing as well as on the wedding and its social and symbolic aspects. To the parallels of this cultural complex identified elsewhere in the Balearic Islands, the author adds others which attest its wide spread, and which suggest that it may date to as far back as the 13th century. 